\title{
REVIEW OF THE INTEGRITY OF A SELF ADMINISTERED MOTIVATIONAL INSTRUMENT
}

\section{Authors:}

Tim Duffy, corresponding author

(Research and International Project Manager)

University of the West of Scotland, University Avenue, Ayr KA8 0SX

Tel 01292886243

Email: tim.duffy@uws.ac.uk

Marie McCaig

(Lecturer)

University of the West of Scotland,

Dudgeon House, Dumfries, DG1 4ZN

Amanda McGrandles

(Lecturer)

University of the West of Scotland, University Avenue, Ayr KA8 0SX

Russell Rimmer

(Emeritus Professor)

School of Business, Enterprise and Management

Queen Margaret University Edinburgh EH21 6UU

and

Hotel and Tourism Management Institute

Sörenberg 6174, Switzeralnd

Colin. R. Martin

(Chair in Mental Health)

University of the West of Scotland, University Avenue, Ayr KA8 0SX

Key words: Motivational Interviewing; Integrity of Motivational Interviewing; Fidelity of Motivational Interviewing; MITI 3.11

(C) 2018. This manuscript version is made available under the CC-BY-NC-ND 4.0 license http:// creativecommons.org/licenses/by-nc-nd/4.0/ 


\section{Review of the integrity of a Self Administered Motivational Instrument.}

\section{Abstract \\ Background}

Motivational Interviewing (MI) was developed by Miller and Rollnick as an evidencebased counselling approach for use in supporting people with alcohol problems. Over the years the principles and spirit of Ml have been reviewed and fine-tuned and the approach has been embraced by practitioners worldwide and across fields.

Since 2001 a number of instruments have been designed to evaluate the fidelity of $\mathrm{MI}$ practice. For the purposes of this study, one such instrument is used to assess a selfadministered motivational instrument, known as the SAMI, which takes the interviewer role.

\section{Objectives}

The SAMI is evaluated against the MITI 3.1.1, which is designed to assess the extent to which $\mathrm{Ml}$ interventions perform on five global dimensions. These are evocation, collaboration, autonomy/support, direction and empathy.

\section{Design}

The SAMI was assembled based on the principles and spirit of MI, problem solving and goal-setting. The targeted behaviour changes were student learning styles and approaches to study.

\section{Setting}

The SAMI was distributed, completed and submitted electronically via the university virtual learning environment.

\section{Participants}

Thirty three mature students of a university delivered online nursing programme were invited to complete the SAMI. Of these, 25 submitted completed transcripts.

\section{Methods}

Transcripts of a sample of six completed SAMIs were assessed by a group of teachers and researchers with experience in the use and evaluation of $\mathrm{MI}$, using five-point Likert scales to assess the SAMI on the five dimensions.

\section{Results}

Overall, an average score exceeding 4.5 was attained across the five dimensions. Conventionally, such a score is recognised as competency in MI. However, on one dimension (empathy), the rating was three. 


\section{Conclusions}

This current research confirms that global principles have been observed in the online delivery of MI using the SAMI to probe approaches to study. 


\section{Introduction}

The purpose of this paper is the evaluation of an instrument devised in the tradition of motivational interviewing (MI), was originally developed as a means of working with clients involved in alcohol and drug use (Miller and Rollnick, 2002). It has also been used in addressing a range of other behaviour changes such as smoking cessation (Emmons and Rollnick, 2001), diabetes (Treasure, 2004) and eating disorders (Treasure and Schmidt 2004). More recently MI has been implemented by healthcare nurses primarily as a method for health promotion practice (Brobeck et al 2011), with Thompson et al (2011) concluding $\mathrm{Ml}$ is effective in changing behaviour in cardiovascular health. Also, in the education of healthcare professionals, MI has been applied to devise a self-administered instrument, called the SAMI (Self-Administered Motivational Instrument) that students can use to review and, where necessary or possible, make amendments to their approaches to higher education (HE) study (Duffy and Rimmer, 2008). The SAMI is considered to be cost effective and time-efficient in assisting students - whether new or returning after a gap - to study effectively, while maintaining a balance with other aspects of their lives.

The SAMI is the instrument evaluated in the research reported in this current paper. It is evaluated using MITI 3.1.1 - Motivational Interviewing Treatment Integrity - devised by, among others Miller, one of the founders of the Ml approach (Moyers et al. 2010). The MITI is also intended to be cost effective and further 'a focussed tool for evaluating MI competence' (Wallace and Turner, 2009). That is, the MITI is designed to assess the extent to which an intervention or treatment matches the requirements of MI. The method of evaluation in the current paper draws on the individual ratings of three university teachers, two of whom are experienced in applying MITI 3.1.1. Once ratings were gathered, concern turned to ensuring that this 'multiple coding' process was consistently applied (Golafshani, 2003). Consequently, the three raters were brought together as a focus group to debate, test and negotiate final ratings and the evaluation. This approach is seen as one form of multiple checking available to a team to ensure overall trustworthiness (Vandall-Walker and Clark 2011; Golafshani, 2003; Morse et al., 2002; Ratcliff, 1995).

The theoretical basis of MI, the SAMI and MITI 3.1.1 are discussed in the next three sections of the paper where relevant literature is reviewed. The approach to assessment, that is the research method for the evaluation of the SAMI using MITI 3.1.1, is set out in the fourth section on Method. In sections following this, evaluation results are presented, discussed, limitations of the research noted and conclusions drawn.

\section{Motivational interviewing}

$\mathrm{MI}$ is considered to be a behaviour-change strategy. Miller and Rollnick (2002, p. 25) define $\mathrm{Ml}$ as 'a client-centred, directive method for enhancing intrinsic motivation to change by exploring and resolving ambivalence'. Ambivalence, sometimes referred to as dissonance, is viewed as: 'A discrepancy between the present state of affairs and how one wants it to be' (Miller and Rollnick, 2002, p. 38). This discrepancy may occur when there is an awareness of, and dissatisfaction with, current behaviour, alongside the recognition of perceived advantages of behaviour change. 
$\mathrm{Ml}$ is more focussed and goal directed than non-directive counselling (White and Miller, 2007). In order to guide the client towards change, guiding principles and specific strategies are used. These guiding principles contribute to the 'spirit' of motivational interviewing which includes, developing discrepancy, rolling with the client's resistance and supporting client's self-efficacy (Miller and Rollnick, 2002, pp. $65-76)$.

The guiding principles provide the foundation or framework for the delivery of MI. Evocation refers to exploration of the client's ideas and values (Miller and Rollnick, 2009). Collaboration incorporates issues relating to client choice and control and shared agenda setting. Client's strengths are utilised through autonomy and the focus on the target behaviour is maintained through direction (Huxley and Copello, 2007; Miller and Rollnick, 2002). These are discussed below in more detail.

Open-ended questions, affirmations, the use of summaries and reflective listening are used with the aim of building client efficacy; developing discrepancy between current behaviour and values; recognizing readiness to change; and rolling with, rather than arguing against, resistance (Miller \& Rollnick, 2002; Rollnick, Miller and Butler, 2008).

Typically the process of MI begins with exploration of the client's current situation. Bundy (2004) shares Miller and Rollnick's (2002) view that in addition to motivation a number of other factors influence behaviour change. These include personal beliefs about the behaviour, the value of the behaviour, the advantages and disadvantages of changing and perceived support from others. Throughout the process the aim of the practitioner is to resolve ambivalence, reflect change talk and support the client to formulate a change plan which reproduces the client's values and desired outcomes (Miller and Rollnick, 2002).

\section{Design of the SAMI (Self-Administered Motivational Instrument)}

The SAMI was designed to support students to improve both their approaches to study and their attainment as measured by academic grade (Duffy and Rimmer, 2009). It was designed as a low cost brief self-help intervention to encourage students to review their current behaviours, consider options and formulate change plans in relation to study approaches (Duffy and Rimmer, 2008).

The self-review element of the SAMI draws on students' analytical skills and encourages reflection on previous experiences. Links to values are also supported through the use of person centred questions such as 'What concerns you about your current approach to study?', and collation of personally relevant information including "What do you think are the obstacles to these plans working out for you'?

Use of 'how' statements within the SAMI aid in defining issues (Chang and Kelly, 1993); these statements also support students' autonomy, choice and control ('How can you put this solution into action?'). Student responses may also highlight differences in relation to the student's stage of change (Prochaska and DiClemente, 1982). 
When formulating change plans, individuals are encouraged to identify personally meaningful activities and engage in goal-directed behaviours (Oettingen and Gollwitzer, 2004; Poulin, Haase, and Heckhausen).

Individual judgements of ability to achieve goals are elicited as the SAMI encourages students to consider behaviour in relation to study and asks them to think about how they would like to change (McGonagle et al, 2008). It further draws on the decisional balance approach of McGowan (1992), as students are invited to consider some positive and negative aspects of their current approach to study.

\section{MITI Overview and summary of other measures}

A number of measures have been developed to assess the integrity of motivational interviewing. Madson and Campbell (2006) and Wallace and Turner (2009) evaluated a range of $\mathrm{Ml}$ integrity measures. The latter identified that 'The degree and quality of psychometric testing performed on them is variable' (Wallace and Turner, 2009, p. 113). While one measure, MISC (Motivational Interviewing Skills Code), performed better in this respect, it has not yet been shown to measure fidelity in the use of MI (Turner and Wallace, 2009).

While not assessing all of the components within the MISC, the MITI can be completed more quickly than the MISC and so provide structured feedback speedily and at lower cost with a view to improving clinical practice.

The MISC is designed to conduct 'detailed process research, investigating the critical elements and causal mechanisms within motivational interviewing' (Moyers et al, 2010, p. 2). In their view, the MITI aims to suggest ways in which practitioners can improve their Ml skills. The MITI presents a reliable assessment of MI treatment integrity (Moyers, Martin, Manuel, Hendrickson, \& Miller, 2005; Pierson et al., 2007). The MITI focuses only on the behaviour of the person conducting the interview whereas the MISC assesses both interviewer and interviewee behaviours. For the purposes of this current study it is interviewer behaviour that is being assessed. Within the structure of self-administered instruments, this means examining the integrity of the SAMI. To do this, the MITI was selected.

Moyers et al acknowledge that the MITI Code is an 'instrument-in-development'. It is designed to assess global scores and behaviour counts. The first component (global scores) 'are intended to capture an overall impression of how well the interviewer meets the intent of the scale' (Moyers et al 2010, p. 3). On the five scales of evocation, collaboration, autonomy/support, direction and empathy, assessors rate interviewer behaviour using five-point Likert scales, where 1 is low and 5 is high. From these ratings, a total Global Clinician Rating is calculated as the average score. An average of 3.5 over the five scales is recognised as 'beginning proficiency' in MI and an average score of 4 or higher is recognised as 'competency' in MI (Moyers et al, 2010, p. 27).

Assessment of behaviour counts may take place as a second stage assessment following review of the global scores. To do this, coders count instances of interviewer behaviour such as open questions or reflections, but are not expected to make any judgement about the quality of the interventions. As this study focuses only on 
identifying the extent to which the SAMI meets the Global Clinician Rating, behaviour counts were not collected.

\section{Methods}

Thirty three students engaged in an online nursing programme in a university in the West of Scotland were invited to complete the SAMI. The University Ethics Committee approved the study and participants provided informed consent prior to the study. They were also assured of confidentiality and anonymity. Participants were British female nurses engaged in year 3 of an academic nursing degree programme. Average age was 37 with an age range of 25-53 years. The SAMI was distributed, completed and submitted electronically via the university virtual learning environment in week two of the programme. Consistent with $\mathrm{MI}$, students had the option to complete the instrument in full, in part or not at all. Twenty five students submitted completed transcripts. Week two was selected for distribution to ensure students had experience of approaches to study in the current environment, allowing them to reflect on issues raised during completion of the instrument. Students completed the SAMI at a time convenient to them and returned the completed document within one week of receiving it. SAMI's were completed in approximately 30 minutes.

Six completed SAMI transcripts were selected for review. These six were representative of the demographic profile of respondents. The transcripts were reviewed by three university teachers and researchers, two of whom had experience applying MITI Global Scores to assess the counselling approaches of Masters-level students.

As the MITI is designed to assess interviewer behaviour and not that of the interviewee, the completed SAMI's provided insight to the overall process students engaged in while completing the SAMI. The team of three researchers did not review interviewee behaviour as this is not expected within the application of the MITI.

Initially, the three researchers individually rated the SAMI against the five MITI Global dimensions, using five-point Likert scales. This was followed by discussion, debate, testing and negotiation among the three operating as a focus group, during which agreed ratings for each scale were decided and confirmed. A rationale for rating each scale was identified based on statements contained within the SAMI (that is, the 'behaviour' of the interviewer) and how these matched against scale criteria noted by Moyers et al (2010). A total rating was calculated by adding the scores awarded for each of the five scales and dividing by five. This average score was then compared with the thresholds of Moyers et al (2010) to identify the extent to which the SAMI meets the MITI requirements. Further details of this are noted below.

\section{Results}

This section contains a review of the MITI global categories and how they are implemented in the SAMI, based on the assessments of the focus group. First, Table 1 provides an overview of results for each global scale, as well as an average global rating score and a 'spirit' global rating score. 
Table 1 Overview of Global Rating Scores of SAMI about here

Next, more detail on focus-group decisions is set out under the following subheadings.

\section{Evocation - Focus group rating: 5}

This scale measures the extent to which the SAMI incorporates the understanding that motivation for change and the ability to move in the direction of change are the responsibilities of the client. On this, the practitioner/SAMI role is to establish reasons for change and to explore ideas around the methods by which change will occur. In general, practitioners scoring highly on evocation are curious about the client's ideas, recognise the significance of eliciting the client's own language in relation to behaviour change and actively create opportunities for that to occur. The focus group awarded a score of 5 , in line with their conclusion that these features are clearly addressed throughout the SAMI. This is demonstrated with examples:

\section{SAMI statement for completion}

'If I continue to study in the way I do now, the drawbacks would be...'

Student responses

'I don't always get things done, sometimes I do but it is a bit frantic. It would be nice to do things calmly'.

\section{SAMI statement for completion}

'If I continue to study in the way I do now, the benefits would be...'

Student response

'Sometimes I get my work done in time but sometimes I don't, it's just the way I've always done it'.

These and other responses demonstrate that the SAMI seeks student reasons for change and statements like 'I will put this into action by...' provide opportunities to describe, in students' own words, how change could occur.

\section{Collaboration - Focus group rating: 4}

This scale measures the extent to which the practitioner interacts with the client and in the current case how effectively this is done in the SAMI. Scoring high on collaboration involves encouraging a client (a student in the current case) to express her or his views and engage in problem solving, resulting in a more equal sharing of power and providing scope for client ideas to have considerable influence. The focus group awarded a score of 4, reporting that the SAMI addresses collaboration successfully because students can have substantial influence on the target behaviour.

Throughout the SAMI there is evidence of these features, as illustrated in the following examples.

\section{SAMI request}

'Try to list as many possible ways of resolving this problem'.

Student response

'Plan study time in advance, go to the library, stop working nights, keep a diary'. 
SAMI question

'If you have not been able to complete all or any of your plan when you review it, can you consider and list ways of altering, amending this in order that you are guaranteed some progress?'

Student response

'I need to ask for help/support from my family. If I ask my mum to look after Katy on a Tuesday afternoon I could go to the library then'.

These responses demonstrate that the student has offered flexible, self-generated solutions based on personally important concerns and ideas, these being essential elements of collaboration (Moyers et al, 2010).

\section{Autonomy / Support - Focus group rating: 5}

This scale measures the extent to which the practitioner supports and actively facilitates client perception of choice as opposed to attempting to control the client's behaviour or choices. Practitioners scoring highly on autonomy/support ensure, either directly or implicitly, that choice and control are actively explored in the interaction. The client is assisted in recognising choices specific to the target behaviour. The practitioner may express optimism about the client's ability to change or they may acknowledge that the client can choose to change the target behaviour or not. The focus group awarded a score of 5 to the SAMI on this MITI dimension, noting that student choice and control is evident throughout the SAMI, as the instrument does not suggest or promote a view of how to study.

Within the SAMI a number of questions closely relate to this scale. The following examples demonstrate this.

\section{SAMI question}

'How can you put this solution into action in a realistic and achievable manner?'

Student response

'l'll spend 30 minutes each day after work writing in my reflective journal'.

\section{SAMI question}

'Having identified some potential obstacles, how can you remove/get around these obstacles?'

Student response

'I will ask the librarian to show me how to do a proper literature search.'

These responses demonstrate "giving credence to personal ideas" (Moyers et al, 2010, p.10) specific to the target behaviour and are indicative of the extent to which the SAMI was intended to promote autonomy and support in decision making.

\section{Direction - Focus group rating: 5}

This scale measures the extent to which practitioners maintain appropriate focus on specific target behaviour or concerns directly relating to it. Practitioners scoring highly on direction ensure that they influence the interaction, not with an intentionally domineering style but by selectively reinforcing client feedback toward the possibility of concern or change with regard to the target behaviour. This involves the recognition of any opportunities to direct the client and to refocus the session should it drift too far from discussion around the target behaviour. Agenda setting includes the target 
behaviour and there should be a focus of possible change rather than the contribution of problem development. The focus group awarded a score of 5 to the SAMI.

The SAMI has a clear focus on target behaviour throughout. The following examples illustrate this:

\section{SAMI question}

'When would be a good time to review this plan... within a few hours, days, weeks or months?

\section{Student response}

'I will review this in 2 weeks time because I plan to start a draft of the first essay by then'.

\section{SAMI question}

'On a score from 1-9 how well do you think you are doing with your study?'

Student response

'I would score myself 3. I'd like to be a 6 . If I was a 6 l'd feel less overwhelmed'.

These examples clearly encourage the student to remain focused on the target behaviour. The structure and logical flow of the SAMI supports this and does not deviate from the target behaviour.

\section{Empathy - Focus group rating: 3}

This scale measures the extent to which understanding of the client's perspective is demonstrated. Practitioners scoring highly have a clear understanding of not just what the client has stated but also what the client means, even though it has not yet been said. This scale was rated 3 by the focus group, indicating the least linkage between the SAMI and MI. The score suggests that there is limited understanding on behalf of the practitioner (that is, the SAMI). Members of the focus group suggested that the SAMI has limitations in relation to the dynamic process of understanding, as there is no provision for the client and practitioner to check that understanding is accurate. Nevertheless, there are aspects of attempting to demonstrate understanding. For example:

\section{SAMI question}

'In what ways are these aspects beneficial to you?'

Student response

'When I avoid studying I tend to spend time cleaning. Having a clean house is important to me'.

\section{SAMI statement}

'The reasons I have for changing my approach to study are...'

Student response

'I'm not sure'.

The first example provides an understanding of the client's values. The second example suggests that the student is unable to generate a reason for changing approach to study. The SAMI provides no mechanism for exploring or differentiating between competing reasons. If the practitioner was present this question could be 
reworded and further exploration around the target behaviour might reveal what was preventing the student from responding to the question.

\section{Discussion}

The SAMI serves the role of the practitioner in that independent completion of the online workbook is encouraged throughout its content and students are invited to explore the reasons for and against change, consider the options available and potentially move towards making plans for change.

Making plans for change involves a student expressing the problem using her or his own terms of reference. This is intended to increase student ownership and control of the process. Using one's own language is also vital in understanding the meaning and significance of the statements used to describe concerns about action or inaction (MINT, 2008). Within the global scale of evocation the maximum score of 5 was awarded by the focus group because there are numerous questions in the SAMI which provide students with the opportunity to define in their own words the specific study problem they face.

Change talk is seen as being a reliable indicator of the level of student internal motivation to change (MINT, 2008). It is the opposite of resistance to change. Eliciting change talk draws the client's attention to his or her internal resources for change and focuses attention on the positive aspect of changing particular behaviour (Miller and Rose, 2009). Students completing the SAMI are encouraged to talk themselves into change while clearly stating the reasons they have for making such change. This process causes students to consider their internal resources and engage in problem solving based on self generated solutions. The focus group awarded a score of 4 for collaboration because this process is influenced by the student rather than the student being directed what to do.

In the early section of the SAMI ambivalence or cognitive dissonance is explored. This is considered an important aspect in the process of change. Students are asked to rate themselves in relation to how well they are doing with their studies and how well they could do if they tried their best. A difference between these scores highlights ambivalence and may increase a student's awareness that there is a need to change approach to study.

A Socratic style of questioning is evident throughout the workbook encouraging the student to give more information when answering questions. This style of open-ended questioning encourages students to investigate and explore their internal thoughts and feelings, while the interviewer (that is, the SAMI) adopts the 'equipoise' approach. Miller (2012) suggests that the use of decisional-balance tools can assist in maintaining 'equipoise', supporting conscious, balanced consideration of both pros and cons. This consideration is supported in the middle section of the SAMI, where students are asked to consider benefits and costs of change.

There are clear benefits to the absence of a practitioner given the practitioner traps which may occur during a brief intervention or motivational session. Previous research highlights the role these traps may have in increasing clients' resistance with the result that the client moves away from change rather than towards it. These traps may 
include the confrontation-denial trap, the expert trap and the question-answer trap (Manuel and Moyers, 2007). The SAMI provides a high level of consistency of approach which has been identified as difficult to achieve in practitioners who have undergone Ml training and supervision (Young, 2010, p 219).

When completing the SAMI there is a risk that the individual may experience difficulties in responding (i.e. being over critical and perhaps, for example, think 'I'm really stupid'). In developing the SAMI, consideration should be given to how such difficulties can be minimised.

Another risk in using the SAMI may be that dimensions of importance and confidence may not be fully explored. These dimensions allow the practitioner to guide the client to review previous attempts at change (Rollnick, Mason and Butler, 1999). While the SAMI clearly incorporates open-ended questions, reflection and the use of summaries, the emphasis on affirmations and strengths within the document could be enhanced. Affirmations build self efficacy, and reinforce the effort the client is making (McCarley, 2009). Future revisions of the SAMI should also focus on this important aspect of encouraging and supporting behaviour change.

The focus group agreed that the SAMI supports autonomy throughout, respecting students' freedom of choice and the implications of any choices made. Evidence for the score of 5 awarded by the group was gleaned through noting broad variation in student responses. Conversely, autonomy may not be consistently supported by practitioners, whose behaviour may compromise clients' autonomy (Vansteenkiste, Williams and Resnicow, 2012).

One of the MITI global elements in which the SAMI scores relatively low is that of empathy. Rogers (1995) considers empathy as a 'process' which involves entering the perceptual world of the other person. Measuring empathy in the SAMI with the MITI proved challenging for two reasons. First, accurate understanding of empathy relies on the student completing the SAMI being detailed in their written responses. The focus group observed that some students at times provided only brief responses or did not provide responses to all questions. While this is quite acceptable within the 'equipoise' approach, it is likely that in a face-to-face interview the interviewer may probe the student further to elicit a response. The second reason is the absence of any feedback mechanism within the SAMI to clarify understanding of what is being portrayed by the student. Consequently this may prevent exploration of deeper meaning therefore hindering appreciation of students' world views and values.

The evaluation process revealed that at least one global score was relevant to each section of the SAMI. For example, in an early section of the SAMI there is the following open question: 'In what way does this bother you, if at all' supporting direction and empathy, while in a later section students are encouraged to generate ideas and set goals, supporting high scores in relation to evocation, autonomy and direction. This overlap of the subscales is common given that "they may both influence and relate to one another" (Moyers et al, 2010, p.4).

\section{Limitations of study}


Moyers et al acknowledge that the MITI 3.11 is still in development and at this point results relating to reliability and validity (of this latest version) are pending. Consequently, the findings of this study must be considered within this context. While the MITI was assessed as appropriate for use within this current study, future research focusing on the integrity of the SAMI might explore the use of other fidelity instruments.

Typically the MITI would be applied by a number of independent coders whereas in this study coders initially rated the SAMI individually before discussing and agreeing on the final ratings with other members of the focus group.

Behavior counts were not coded for the SAMI within this study. This next stage of assessing the integrity of the SAMI will be explored now that positive preliminary results have been obtained for global scale ratings.

\section{Conclusion}

This is a first attempt at evaluating the integrity of a Self Administered Motivational Instrument (SAMI). While there is evidence that the SAMI is a useful instrument in assisting students to improve their approaches to study and their academic attainment, the current research provides initial confirmation that the SAMI has been designed in the 'spirit' of motivational interviewing and rates well on four of five global scores as measured by the MITI. A focus in future could be to improve the aspect of the SAMI scoring poorly - 'empathy' - and reviewing and assessing behavior counts as a further measure of fidelity of the SAMI to MI.

\section{References}

Brobeck, E, Bergh, H, Odencrants, S, Hildingh, C (2011) Primary healthcare nurses' experiences with motivational interviewing in health promotion practice. Journal of Clinical Nursing Vol. 20 3322-3330.

Bundy, C. (2004) Changing Behaviour: Using Motivational Interviewing Techniques. Journal of the Royal Society of Medicine. Vol. 97(Suppl 44), 43-47.

Chang, R.Y. and Kelly, P.K. (1993) Step-by step problem solving. California. Richard Chang Associates.

Duffy, T, Rimmer R (2008) Improving Students' Motivation to Study. Reflect Press Ltd. Devon, UK.

Duffy, T, Rimmer R (2009) A review of the positive impact of a Self Administered Motivational Instrument (SAMI) on Deep and Strategic approaches to study and on academic attainment. Reflecting Education Vol 5, No. 2, May 2009, 104-115.

Emmons, K. and Rollnick, S. (2001) Motivational interviewing in health care settings: opportunities and limitations. American Journal of Preventive Medicine. Vol. 20(1), 6874. 
Golafshani, N. (2003) Understanding reliability and validity in qualitative research. The Qualitative Report, 8 (4), pp.597-607. Available online:

http://www.nova.edu/ssss/QR/QR8-4/golafshani.pdf (Accessed 25 June 2010).

Huxley, A. and Copello, A. (2007) An overview of psychological interventions for addictive behaviours. In: Day, E. (ed.) Clinical topics in addiction. London, Royal College of Psychiatrists

Manuel, J.K. and Moyers, T.B (2007) Introduction to Motivational Interviewing Training Manual: Developed for the TEAM Project. USA.

Madson, M.B. and Campbell, T.C. Measures of fidelity in motivational enhancement: A systematic review. Journal of Substance Abuse Treatment 31 (2006), 67- 73.

McGonagle, I., Baguley, I., Owen, S. and Lewis, S. (2008) In Stickley, T and Basset, T. Learning about mental health practice. Wiley and Sons. England.

McGowan, A.L., Evaluation of motivational interviewing in the treatment of alcohol related problems. M.Phil Thesis, Paisley College of Technology, 1992.

Miller, W (2012) Equipoise and Equanimity in Motivational Interviewing. MITRIP Vol 1 , No 1

Miller, W. and Rollnick, S. (2002) Motivational interviewing: preparing people for change, $2^{\text {nd }}$ ed. New York: Guilford Press.

Miller W.R. \& Rollnick S. (2009) Ten things that motivational interviewing is not. Behavioural and Cognitive Psychotherapy 37, 129-140.

Miller W.R. \& Rose G.S. (2009) Toward a theory of motivational interviewing. The American Psychologist 64, 527-537.

Morse, J. Barratt, M. Mayan, M. Olsen, K. and Spiers, J. (2002) Verification Strategies for Establishing Reliability and Validity in Qualitative Research. International Journal of Qualitative Methods, 1 (2), pp.13-22.

Moyers TB, Martin T, Manuel JK, Hendrickson SML, Miller WR. (2005) Assessing competence in the use of motivational interviewing. Journal of Substance Abuse Treatment.;28:19-26.

Moyers, T.B., Martin, T., Manuel, J.K., Miller, W.R \& Ernst, D. Revised Global Scales: Motivational Interviewing Treatment Integrity 3.1.1 (MITI 3.1.1). University of New Mexico. Center on Alcoholism, Substance Abuse and Addictions (CASAA). Revised January 2010.

Motivational Interviewing Network of Trainers (MINT) (2008)_Motivational Interviewing training for new trainers [Online]. Available at:

http://www.motivationalinterviewing.org/ (accessed 28 June 2011). 
Oettingen, G., and Gollwitzer, P. M. (2004). Goal setting and goal striving. In M. B. Brewer \&M. Hewstone (Eds.), Emotion and motivation (165-183). Malden, MA: Blackwell Publishing.

Pierson, H. M., Hayes, S. C., Gifford, E. V., Roget, N., Padilla, M., Bissett, R., et al. (2007). An examination of the Motivational Interviewing Treatment Integrity code. Journal of Substance Abuse Treatment, 32, 11-17.

Poulin, M., Haase, C., \& Heckhausen, J. (2005). Engagement and disengagement across the life span: An analysis of two-process models of developmental regulation. In W.Greve, K. Rothermund, \& D. Wentura (Eds.), The adaptive self: Personal continuity and intentional self-development (117-135). New York: Hogrefe.

Prochaska J.O., Di Clemente, C.c (1982) Transtheoretical theory: towards a more integrated model of change. Psychotherapy: theory, research and practice, 19, 276 288.

Rash E (2008) Simulating Health Promotion in an Online Environment Journal of Nursing Education_Vol 47 no 11, 515-517.

Ratcliff, D. (1995) Validity and Reliability in Qualitative Research. Available online: http://qualitativeresearch.ratcliffs.net/Validity.pdf (Accessed: 25 June 2010).

Rogers, C. (1995) A Way of Being. Boston: Houghton Miffin Company

Rollnick S, Mason P, Butler C. (1999) Health behavior change: a guide for practitioners. Churchill Livingstone.

Rollnick S., Miller W., and Butler C. (2008) Motivational Interviewing in Health Care: Helping Patients Change Behavior. [Online]. The Guildford Press: New York. Available:http://www.netlibrary.com/urlapi.asp?action $=$ summary $\& v=1 \&$ bookid $=21744$ 7 [5 May, 2011].

Thompson, D.R., Chair, S.Y., Chan, S.W., Astin, F, Davidson, P., Ski, C (2011) Motivational interviewing: a useful approach to improving cardiovascular health? Journal of Clinical Nursing Vol 20, 1236-1244.

Treasure, J. (2004) Motivational Interviewing Advances in Psychiatric Treatment. Vol. 10, 331-337.

Treasure J. \& Schmidt U. (2004) Anorexia nervosa. Clinical Evidence 12, 1192-1203.

Turner, F., Wallace, L. (2009). Is motivational interviewing skills code (MISC) Validated for use? A systematic review of psychometric evidence. Unpublished doctoral dissertation, Queen Margret University, Edinburgh, UK.

Vandall-Walker, V., Clark, A. (2011) It starts with access! A grounded theory of family members working to get through critical illness, Journal of Family Nursing, 17:1, 148181 
Vansteenkiste, M., Williams, G and Resnicow, K (2012) Toward systematic integration between self-determination theory and motivational interviewing as examples of topdown and bottom-up intervention development: autonomy or volition as a fundamental theoretical principle. International Journal of Behavioral Nutrition and Physical Activity , 9:23

Wallace, L and Turner, F. A Systematic Review of Psychometric Evaluation of Motivational Interviewing Integrity Measures. Journal of Teaching in the Addictions, 8:1-2, 84-123.

White W.L. \& Miller W.R. (2007) The use of confrontation in addiction treatment: History, sciences and time for change. Counselor 8, 12-30.

\section{Global scale}

Evocation

Collaboration

Autonomy/Support

Direction

Empathy

Average Global Rating

(average of all five Global Ratings)

Spirit Global Rating

(average of evocation, collaboration, and autonomy/support

scores)

Global Clinician
Ratings
5
4
5
5
3
4.40
4.67

Table 1 Overview of Global Rating Scores of SAMI 